\title{
Resveratrol inhibits hypoxia-induced glioma cell migration and invasion by the p-STAT3/miR-34a axis
}

\author{
H. WANG, H. FENG, Y. ZHANG* \\ Key Laboratory of the Ministry of Education for Experimental Teratology, Shandong Provincial Key Laboratory of Mental Disorders, Department \\ of Histology and Embryology, Shandong University School of Medicine, Jinan, China
}

*Correspondence: ymzhang@sdu.edu.cn

Received October 26, 2015 / Accepted December 30, 2015

\begin{abstract}
Hypoxia promotes aggressiveness, angiogenesis and resistance in glioma. It has been reported that resveratrol has strong anti-tumor ability and can inhibit migration and invasion of varieties of tumor including glioma. However, whether resveratrol inhibits hypoxia-induced migration and invasion of glioma cells is still unknown. In this study, we found glioma U87 and U251 cells migration and invasion was reduced by resveratrol under hypoxia condition and higher doses led to stronger block, while proliferation of U87 and U251 cells was hardly effected. Mechanically, hypoxia-induced upregulation of phosphorylated signal transducer and activator of transcription 3(p-STAT3) was blocked by resveratrol. MicroRNA-34a (miR-34a) is a tumor suppressor whose promoter region has a conserved STAT3-binding site and can be negatively regulated by STAT3. Interestingly, miR-34a was downregulated under hypoxia but upregulated by resveratrol which was perhaps relevant to changes in level of p-STAT3. The effect of resveratrol on p-STAT3 and miR-34a was both time-and dose-dependent. Summarizing, resveratrol inhibits hypoxia-induced migration and invasion possibly via p-STAT3/miR-34a axis and this effect is both time-and dose-dependent.
\end{abstract}

Key words: resveratrol, hypoxia, glioma, miR-34a, p-STAT3

Glioma is a class of the most frequent primary malignant tumors in central nervous system (CNS), which is hardly curable so far $[1,2]$. Gliomas show high morbidity and mortality due to their strong aggressiveness. This aggressive phenotype is possibly relevant to hypoxia, which is one of the most remarkably characteristics of glioma microenvironment and might play a crucial role in glioma growth, development, and angiogenesis [3]. It has been documented that hypoxia also induces migration and invasion of glioma cells [4-6], which involves a series of transduction pathways and signal molecules.

One of these molecules is STAT3 which plays an important part in hypoxia-induced migration and invasion [7]. STAT3 is

\footnotetext{
Abbreviations: p-STAT3 - phosphorylated signal transducer and activator of transcription; miR-34a - microRNA-34a CNS - central nervous system; EGFR - pidermal growth factor receptor; VEGFR - vascular endothelial growth factor receptor; PDGFR - plate-let derived growth factor receptor; siRNA - small interfering RNA; BBB - blood-brain barrier; MMP - matrix metalloproteinases
}

activated by phosphorylation of single tyrosine residue located at position 705 [7]. This phosphorylation can be catalyzed by varieties of tyrosine kinases including such receptors with intrinsic tyrosine kinase activity as epidermal growth factor receptor (EGFR), vascular endothelial growth factor receptor (VEGFR), plate-let derived growth factor receptor (PDGFR) $[8,9]$. p-STAT3 forms into dimers and translocates to nucleus, where it is involved in the regulation of transcription activity of target genes [8].

Accumulating evidence including ours has shown that STAT3 is overexpressed and activated in many tumors including breast cancer, prostate cancer and glioma [10-13]. STAT3 is a promising target for therapeutic intervention for it is involved in multiple oncogenic signaling cascade [14] relevant to cell transformation, cellular apoptosis, proliferation, migration and invasion $[8,15]$. STAT3 also initiates and regulates mesenchymal transformation in malignant gliomas [14]. It has been found that STAT3 knockdown by small interfering RNA (siRNA), microRNA (miR) or small molecule inhibitors shows anti-tumor effects [16-19]. 
MicroRNAs are non-coding RNAs which have an important effect on regulating gene expression and show a promising potential in tumor treatment [20]. MiR-34 family plays an important role in tumor suppression [21]. The miR-34 family consists of miR-34a, miR-34b and miR34c; miR-34a has its own transcript while miR-34b and miR-34c share one primary transcript. It has been reported that miR-34a is downregulated in multiple types of cancer $[21,22]$. As a tumor suppressor, miR-34a regulates its target genes to inhibit malignant biological properties of cancer including metasis and invasion. MatjazRokavec et al. found IL-6-induced EMT and invasion of CRC cells are mediated via direct repression of miR-34a by STAT3 [23], which indicates p-STAT3/miR-34a might participate in tumor malignant behaviors.

Resveratrol (Res) is a kind of polyphenol present in grapes, berries, peanuts and wine [24-26]. It has a protective effect on stress, injury, ultraviolet irradiation and fungal infection [27]. It has been demonstrated that resveratrol also has lots of other bioactivities [28] including cardiovascular-protection, antiinflammation, anti-aging effect $[28,29]$. Recent findings indicate resveratrol has strong anti-tumor potential against various types of cancer [27]. Resveratrol can inhibit tumor metasis [28, 29] and invasion [29-31] as well. Castino R et al. found resveratrol reduces glioma migration and invasion under normoxia [32]. However, there have been no studies showing whether resveratrol has such tumor suppression effect under hypoxia.

In this study, we demonstrated resveratrol inhibits hypoxiainduced glioma cells migration and invasion and this effect was both time-and dose-dependent, while cell growth was barely influenced by resveratrol of selected concentration. Our results also show resveratrol might exert its function via p-STAT3/miR-34a axis. This study could provide in vitro experimental evidence for resveratrol used for glioma treatment and STAT3/miR-34a axis as a potential therapeutic target of malignant glioma.

\section{Materials and methods}

Cell culture and reagents. Human glioblastoma cell lines (U87 and U251) were obtained from American Type Culture Collection (Manassas, VA, USA). All cell lines were cultured in $25 \mathrm{~mm}^{2}$ culture bottles with high glucose Dulbecco's modified Eagle's medium (DMEM/HG, Gibco, Invitrogen Life Technologies, Barcelona, Spain) supplemented with $10 \%$ fetal bovine serum (FBS), penicillin $(100 \mathrm{U} / \mathrm{mL})$, and streptomycin $(100 \mathrm{lg} / \mathrm{mL})$ in a humidified $5 \% \mathrm{CO}_{2}$ atmosphere at $37^{\circ} \mathrm{C}$. Cobaltchloride $\left(\mathrm{CoCl}_{2}\right)$ was added to culture medium to mimic hypoxia condition with a concentration of $100 \mathrm{mM}$. Resveratrol was purchased from Sigma (StLouis, MO, USA) and diluted with DMSO.

BrdU Cell Proliferation Assay. A BrdU Cell Proliferation Assay Kit (6813, Cell signaling technology, MA, USA) was used to study the effect of selected concentration resveratrol on cell proliferation. Briefly, U251 and U87 cells at a density of $1 \times 10^{4} /$ well were plated into a 96-well plate with medium contained $\mathrm{CoCl}_{2}$ and DMSO (control) or $20 \mu \mathrm{M}$ resveratrol or $40 \mu \mathrm{M}$ resveratrol. Then BrdU was added to plate wells. After $24 \mathrm{~h}$ incubation, cell proliferation assays were conducted according to the manufacturer's protocol. All experiments were carried out in five wells and repeated in three times.

Cell wound healing assay. Cells were seeded on 6-well culture dishes. Cell wound was made by scratching monolayer of cells with $200 \mu \mathrm{M}$ pipette tips and then wash the cells with D-Hanks buffer for 3 times to remove floating cells in the medium. After that, medium with $\mathrm{CoCl}_{2}$ and different concentrations of Res or DMSO (control) was added. Cells were then incubated at $37^{\circ} \mathrm{C}$ for $24 \mathrm{~h}$. Photos were taken before and after incubation and used to calculate mean migration distance by measuring 10 different migration distances randomly. Assays were conducted three times.

Transwell assay. Cells were incubated in serum-free $\mathrm{DMEM} / \mathrm{HG}$ for $6 \mathrm{~h}$ prior to seeding in $200 \mu \mathrm{l}$ serum-free medium with $100 \mu \mathrm{M} \mathrm{CoCl}_{2}$ and different concentrations of Res or DMSO (control) in transwells (Corning, NY, USA). In the meantime, $600 \mu \mathrm{l}$ medium containing $10 \%$ FBS was used as a chemoattractant and added into the bottom chamber. After $24 \mathrm{~h}$ incubation at $37^{\circ} \mathrm{C}$, non-migratory cells on the upper surface of the chamber were scrubbed gently by a cotton swab. $0.1 \%$ crystal violet diluted in PBS was used to stain migratory cells attached to the bottom surface. Stained migratory cells was photographed and counted under a microscope in ten random fields. Assays were conducted three times.

Western blot. Protein isolation was carried out by using radioimmunoprecipitation assay (RIPA) buffer containing PMSF and phosphatase inhibitor. All samples were loaded onto 10\% SDS-polyacrylamide gel electrophoresis (PAGE) and then transferred to PVDF membrane (Millipore Corp., Bedford, MA, USA) in transfer buffer. 5\% nonfat milk diluted in TBST was used for block. After that, the membrane was incubated in primary antibodies: STAT3 antibody (sc-482; Santa Cruz Biotechnology, Santa Cruz, CA,USA), p-STAT3 (9145S;Cell signaling technology, MA, USA) and $\beta$-actin (3700S; Cell signaling technology, MA, USA). After three washes for $15 \mathrm{~min}$ with TBST, membranes were incubated in secondary antibodies: anti-mouse IgG, HRP-linked antibody (7076S; Cell signaling technology, MA, USA) and anti-rabbit IgG, HRP-linked antibody (7074S; Cell signaling technology, MA, USA). Chemiluminescence assay was conducted to reveal the antigens.

RNA isolation and real-time PCR. Total RNA was extracted from cells by using TRIzol (Invitrogen, CA, USA). Reverse transcription was carried out by ReverseAid First Strand cDNA Synthesis Kit (Thermo Fisher Scientific, MA, USA) according to protocol. Real-time PCR was conducted in the icycler iQ multicolor real-time PCR detection system (Bio-Rad, Richmond, California) using HotStart SYBR Green qPCR Master Mix (Excell Bio, Shanghai, China). Specific premier was synthesized by Ribobio CO., LTD. (Guangzhou, China) to measure the level of miR-34a. U6 was chosen to be 


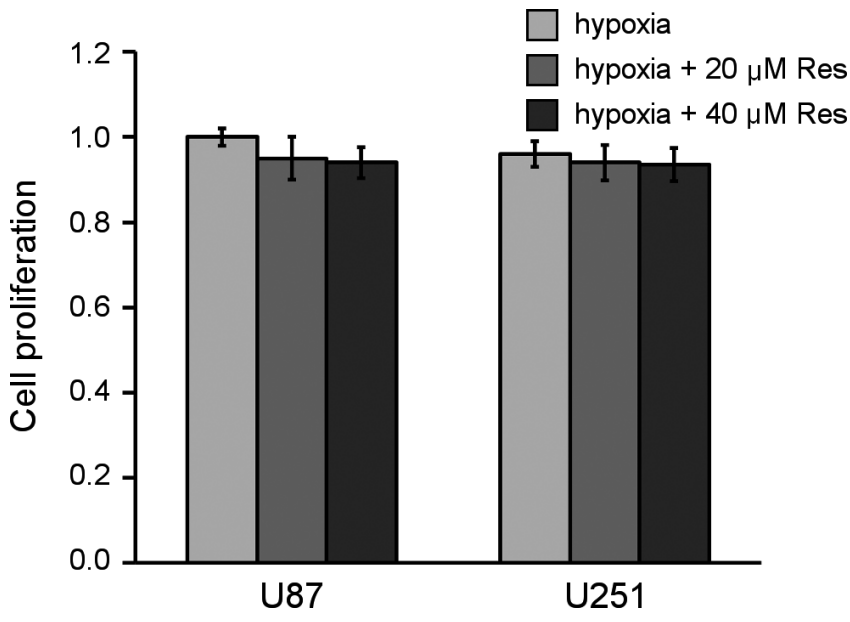

Figure 1. Effect of selected concentration resveratrol on U251 and U87 cell proliferation. Certain numbers of U87 and U251 cells were plated into a 96-well plate in medium supplied with $\mathrm{CoCl}_{2}$ and DMSO or resveratrol of indicated concentration.

the internal control and its premier was also synthesized by Ribobio CO., LTD.(Guangzhou, China). All samples were run for three times. Results were normalized by corresponding U6 content.

Statistical analysis. All data were expressed as the means \pm SE (standard error). Significances between groups were determined by using Student's t-test. Representative results of experiments were repeated at least 3 times. The level of significance was $p<0.05$.

\section{Results}

Resveratrol of selected concentration hardly influences U251 and U87 cells proliferation. The aim of this study is to explore the effect of resveratrol on hypoxia-induced glioma migration and invasion. However, if cell proliferation is remarkably influenced by resveratrol, changed cell numbers could cause false positive results in migration and invasion assays. So we determined the effect of selected concentration resveratrol on U251 and U87 cells proliferation under hypoxia by using a BrdU cell proliferation assay. According to our static analysis, proliferation activities of U251 cells and U87 cells were reduced to $95.01 \%$ and $97.91 \%$ respectively in response to $20 \mu \mathrm{M}$ resveratrol and $94.03 \%$ and $96.95 \%$ respectively in response to $40 \mu \mathrm{M}$ resveratrol (Fig. 1). The results showed selected concentration resveratrol has very limited effect on glioma cells proliferation.

Resveratrol inhibits hypoxia-induced migration of U251 and U87 cells. Hypoxia is a remarkable feature of glioma microenvironment and has activity of migration induction. To investigate the effect of resveratrol on hypoxiainduced migration, cell wound healing assay was performed. Representative photos are showed in Fig. $2 \mathrm{a}$ and column diagram is showed in Fig. 2b. As results showed, under hypoxia condition cell wound healing of U87 and U251 was markedly accelerated but this promotion was inhibited by resveratrol. After static analysis, we found migration activity was increased by $129.87 \%$ (U87) and 94.34\% (U251) when compared with normoxia. But this promotion was inhibited by $63.07 \%$ (U87) and $53.60 \%$ (U251) when cells were supplied with $20 \mu \mathrm{M}$ resveratrol at the same time and by $74.85 \%$ (U87) and $62.07 \%$ (U251) when $40 \mu \mathrm{M}$ resveratrol was supplied. The results suggest resveratrol inhibits hypoxia-induced migration of U87 and U251 cells and its effect might be dose-dependent. Higher concentration could lead to stronger inhibition.

Resveratrol inhibits hypoxia-induced invasion of U251 and U87 cells. To evaluate the relationship between resveratrol and hypoxia-induced invasion of glioma cells, transwell assay was conducted. Images in Fig. 3a show there were more cells which pass through the matrigel under hypoxia than normoxia after 24-hour incubation. However, when culture medium was mixed with $20 \mu \mathrm{M}$ and $40 \mu \mathrm{M}$ resveratrol, number of cells that penetrated the matrigel showed a reduction and cells with $40 \mu \mathrm{M}$ resveratrol were less than $20 \mu \mathrm{M}$. To quantize this effect of resveratrol on hypoxia-induced invasion, we counted cell numbers of ten fields which were chosen randomly under microscopy. Bar chart was present in Fig. 3b. Invasiveness was promoted by 2.19-fold (U87) and1.95-fold (U251) in response to hypoxia stimuli. But this increase was blocked by $20 \mu \mathrm{M}$ and $40 \mu \mathrm{M}$ resveratrol which was found in both U87 and U251. The results showed resveratrol inhibited hypoxia-induced invasion and this inhibition might also be dose-dependent.

Hypoxia-induced activation of STAT3 is inhibited by resveratrol in $\mathrm{U} 251$ and $\mathrm{U} 87$. It has been documented that activated STAT3 might play a role in malignant tumor properties. To study if activated STAT3 is involved in inhibition of hypoxia-induced migration and invasion by resveratrol, we determined the expression of p-STAT3 and STAT3 in both U251 and U87 cells by Western Blot. Level of p-STAT3 in U251 increased when cells were under hypoxia for 24h (Fig. 4a) and 48h (Fig. 4c), while total STAT3 remained no change in response to hypoxia (Fig. 4a, 3c). When U251 cells were incubated with resveratrol of different concentrations under hypoxia for $24 \mathrm{~h}$, levels of p-STAT3 showed reduction to verifying degrees (Fig. 4a). The higher resveratrol concentration was, the lower level of p-STAT3 got. When U251 cells were incubated with $20 \mu \mathrm{M}$ resveratrol under hypoxia for different time, levels of p-STAT3 also showed reduction to verifying degrees (Fig. 4c). The longer resveratrol was present in culture medium, the lower level of p-STAT3 was. We found similar pattern of changes in levels of p-STAT3 in U87 cells (Fig. 4b, $4 \mathrm{~d})$. The results indicate resveratrol inhibits hypoxia-induced overexpression of p-STAT3 and its effect might be both timeand dose-dependent.

miR-34a is induced by resveratrol in U87 and U251. To study whether miR-34a is involved in regulation of resveratrol 
in hypoxia-induced migration and invasion, we determined the level of miR-34a of U87 cells by real-time PCR. Level of miR-34a was downregulated when cells were under hypoxia (Fig. 5a, 5a). But after incubation in resveratrol with different concentrations for $24 \mathrm{~h}$ (Fig. 5a) or $20 \mu \mathrm{M}$ resveratrol for different time (Fig. 5b), level of miR-34a increased to verifying degrees. The higher concentration of resveratrol is or the longer incubation in resveratrol is, the higher miR-34a level is. The results suggest miR-34a might involve in the regulation of resveratrol in hypoxia-induced migration and invasion (Fig. 5c).

\section{Discussion}

As mentioned previously, glioma is a common brain tumor which is hard to cure at present due to high rate of relapse [ 1 , 2]. Hypoxia is an important feature of glioma microenvironment leading to intratumoral necrosis and angiogenesis [3].
Hypoxia is implicated in promoting glioma aggressiveness, chemoresistance and antiangiogenic therapy [3]. Glioblastoma has strong activity of migration and invasion [2], which is associated to low oxygen condition of tumor microenvironment [4-6]. Thus it's essential to find a way to block hypoxia-induced migration and invasion.

Resveratrol, a kind of polyphenol, is a potential and promising anti-tumor drug which is able to pass through the blood-brain barrier (BBB) [33]. There are lots of evidence suggesting that resveratrol can inhibit cell migration and invasion under normoxia and but its mechanisms are poorly understood $[34,35]$. In this study, we found resveratrol also showed similar effect under hypoxia. The cell wound healing assay and transwell asssay results showed resveratrol inhibited hypoxia-induced migration and invasion. We also observed inhibitory effect of $40 \mu \mathrm{M}$ resveratrol is stronger than $20 \mu \mathrm{M}$, which indicates its inhibitory effect might be dose-dependent. Then BrdU assay was performed to explore whether prolifera-
A
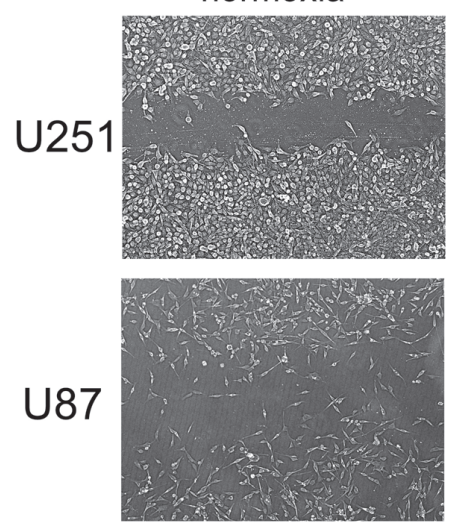

hypoxia
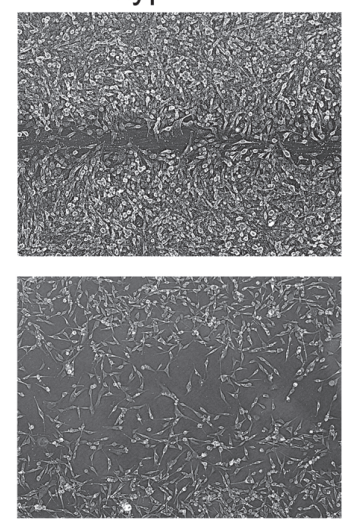
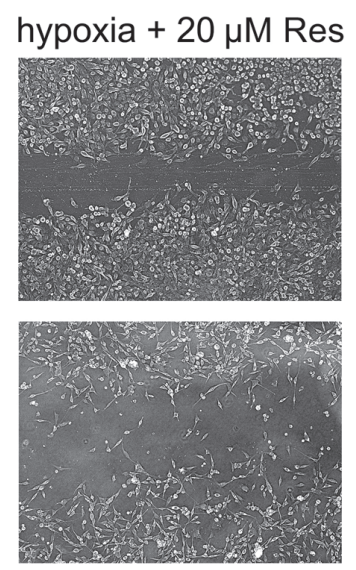
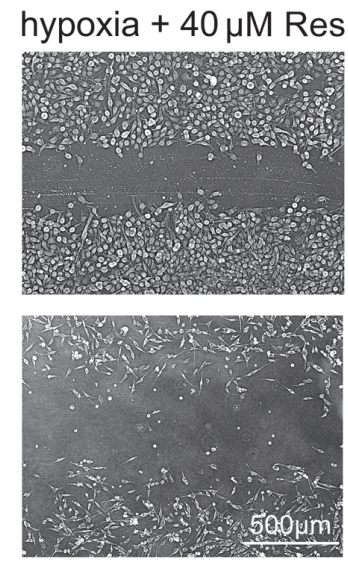

B

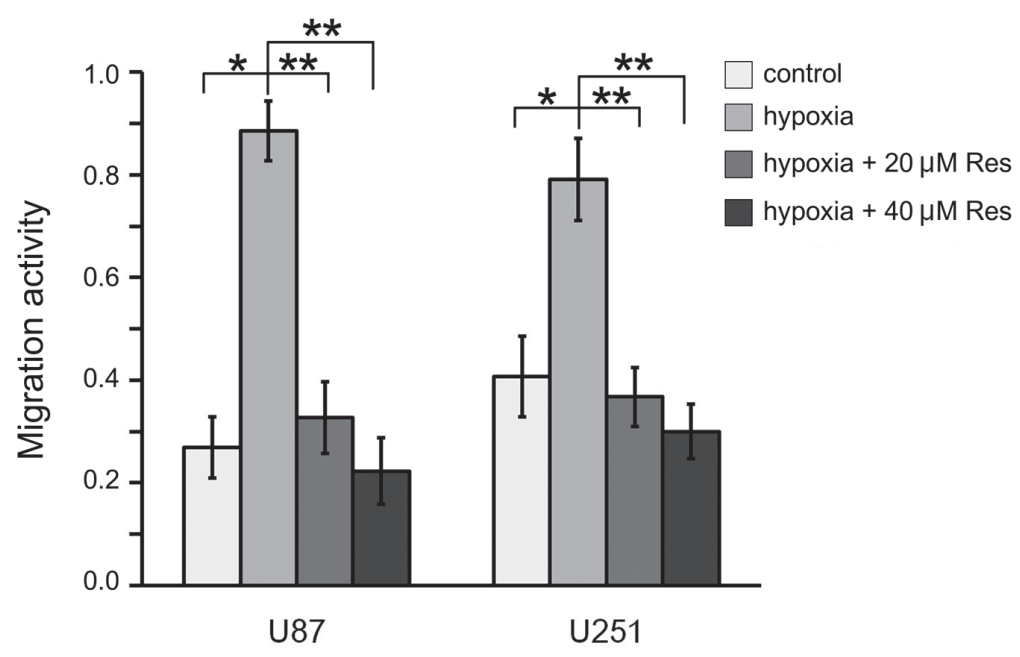

Figure 2. Effect of resveratrol on hypoxia-induced migration of glioma cells U87 and U251. A Monolayer of U87 or U251 cells were scratched by $20 \mu 1$ pipette tips with or without indicated presence of resveratrol and then exposed to normoxia or $\mathrm{CoCl}_{2}$-mimic hypoxia. $\mathrm{B}$ Quantitative results of cell wound healing assay are showed. All data are calculated from three independent experiments. ${ }^{\star}$ means $P<0.05,{ }^{\star *}$ means $P<0.01$. 
tion inhibition accounted for aggressiveness suppression. The proliferation assay results demonstrated resveratrol of selected concentration hardly influence cell growth, which provides a further proof that resveratrol inhibits cell motion rather than cell proliferation.

STATs family plays an important role in normal cytokines signaling and development [10], of which STAT3 is particularly essential in crucial cell function including maintance of cell transformation, cell cycle and apoptosis, migration and invasion $[8,10]$. STAT3 signaling accelerates cell cycle by upregulation of Cyclin D1 and cMyc [36], helps cells survive apoptosis [37] and contributes to tumorigenesis. STAT3 is required for cells motility and STAT3 inhibition could reduce cell migration [38], which might be relevant to its effect on microtubule dynamics [39]. STAT3 is also involved in regulation of matrix metalloproteinases (MMPs) [40-42], which is a crucial enzyme for cancerous cells invasion disrupting extracellular matrix. Thus STAT3 is now regarded as a significant potential therapeutic target for varieties of tumors including glioma [43] and it's important to know how STAT3 regulates its targets and be regulated.
miRNAs are small non-coding RNAs which might be key players in tumorigenesis and promising in cancer treatments [44]. Recent researches also show miRNAs act as crucial regulators in response to hypoxia [45]. In the last few years, it is reported that STAT3 can be regulated by some specific miRNAs such as miR-21 [46], miR-125a [47], miR-23a [48] et al. However, further research is needed to illustrate how STAT3 is regulated by miRNAs and regulates miRNAs. miR-34a is a tumor suppressor microRNA and was found to inhibit proliferation, migration and invasion of breast cancer, prostate cancer and hepatocellular carcinoma [49-51]. There is a phylogenetically conserved STAT3-binding site located in the first intron of miR-34a genomic region [23]. When activated by phosphorylation, STAT3 is dimerized and translocated into nucleus and binds to that site to regulate the level of miR-34a [23].

As many research showed including ours, when cells are under hypoxia stimuli, levels of p-STAT3 and miR-34a will be upregulated and downregulated respectively $[52,53]$. In our study, Western blot and RT-PCR results showed resveratrol
A

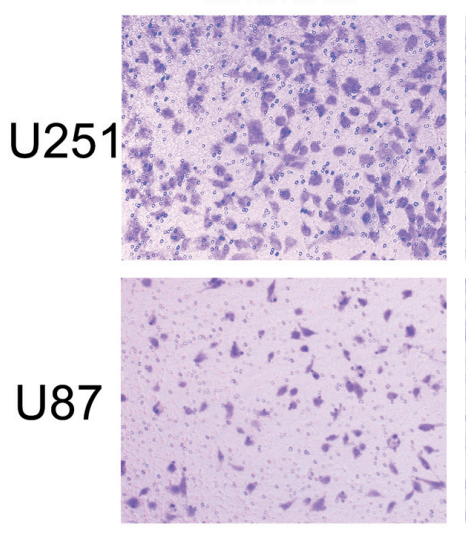

hypoxia

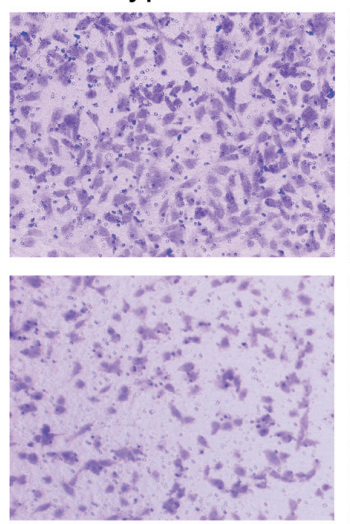

hypoxia $+20 \mu \mathrm{M}$ Res hypoxia $+40 \mu \mathrm{M} \operatorname{Res}$
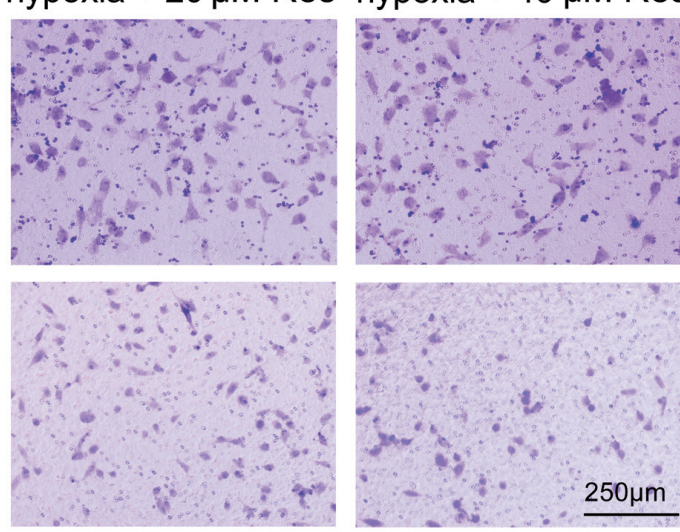

B

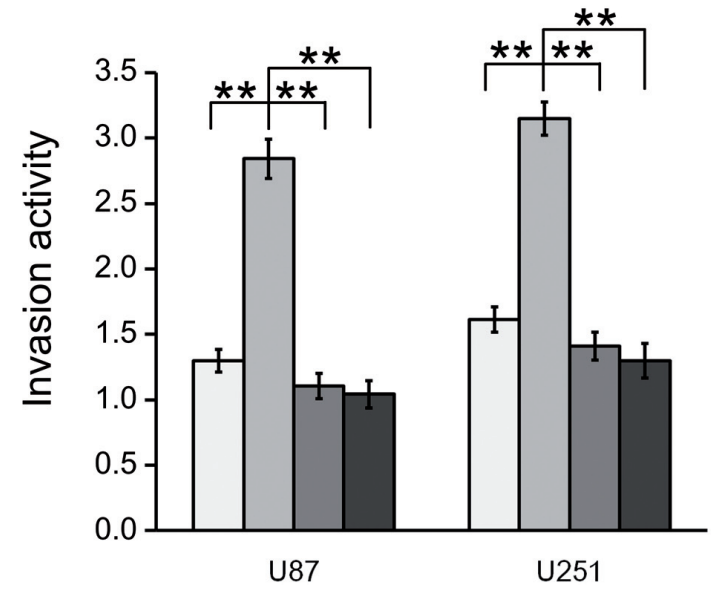

Figure 3. Effect of resveratrol on hypoxia-induced invasion. A Transwell assay was conducted to determine invasion activity of cells. Invaded cells were stained by $0.1 \%$ crystal violet. B Quantitative results are represent. Mean number of invaded cells was calculated from at least 10 random fields under microscope. All experiments were repeated independently for 3 times. ${ }^{\star \star}$ means $P<0.01$. 

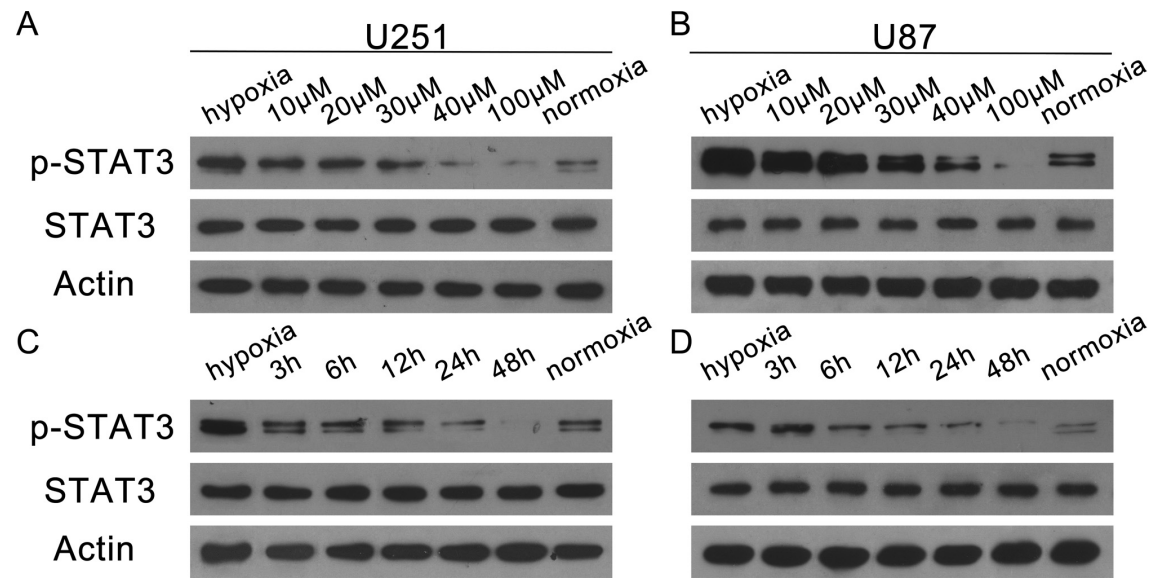

Figure 4. Effect of resveratrol on activation of STAT3 in glioma cells U87 and U251. A,B U251or U87 cells were treated in CoCl-mimic hypoxia or normoxia with or without presence of indicated resveratrol of different concentrations for $24 \mathrm{~h}$. C,D U251 and U87 cells were incubated in CoCl ${ }_{2}-\mathrm{mimic}$ hypoxia or normoxia for indicated different time with or without presence of $20 \mu \mathrm{M}$ resveratrol.

inhibited hypoxia-induced activation of STAT3 and downregulation of miR-34a, which indicates p-STAT3 and miR-34a might involve in regulation of resveratrol in hypoxia-induced migration and invasion and its effect is both time-and dosedependent. That is to say, resveratrol functions as a suppressor of hypoxia-induced migration and invasion possibly via p-STAT3/miR-34a axis. Nevertheless, more evidence will be needed to confirm this axis in glioma.

To conclude, this study demonstrates that resveratrol inhibits hypoxia-induced migration and invasion of glioblastoma
A

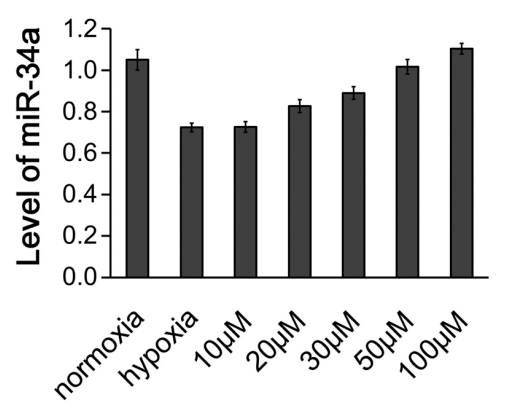

B

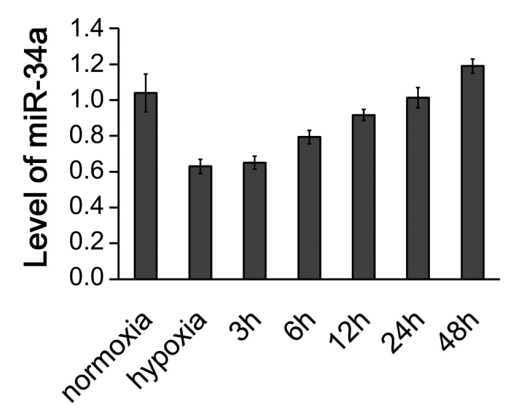

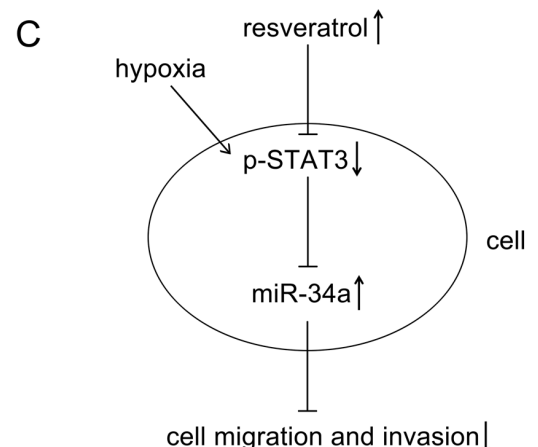

Figure 5. Effect of resveratrol on hypoxia-induced downregulation of miR-34a in glioma U87 cells. A U87 cells were incubated under indicated CoCl ${ }_{2}$ mimiced hypoxia or normoxia for $24 \mathrm{~h}$ with or without resveratrol of different concentrations. $\mathrm{B} \mathrm{U}_{87}$ cells were incubated under indicated $\mathrm{CoCl}_{2}$-mimiced hypoxia or normoxia for different time with or without $20 \mu \mathrm{M}$ resveratrol. C Resveratrol's inhibitory effect on hypoxia-induced migration and invasion might via p-STAT3/miR-34a pathway. 
cells U251 and U87 and its effect is possibly via p-STAT3/miR$34 \mathrm{a}$ axis. These data give a new insight into our understanding about mechanisms of how resveratrol functions as a tumor suppressor and support the use of resveratrol as a therapeutic antitumor agent.

Acknowledgements: This work was supported by National Natural Science Foundation of China (No. 81402059); China Postdoctoral Science Foundation (No. 2012M521351); Shandong Natural Science Foundation (No.ZR2012HQ010); Shandong Postdoctoral Science Foundation (No. 201203049).

\section{References}

1[1] Van Gool SW Brain tumor immunotherapy: What have we learned so far?. Front Oncol 2015; 5: 98

[2] GANAU L, PARIS M, LIGAROTTI GK, GANAU M Management of Gliomas: Overview of the Latest Technological Advancements and Related Behavioral Drawbacks. Behav Neurol 2015; 2015: 862634

[3] WOMELDORFF M, GILLESPIE D, JENSEN RL Hypoxiainducible factor-1 and associated upstream and downstream proteins in the pathophysiology and management of glioblastoma. Neurosurg Focus 2014; 37: E8 http://dx.doi. org/10.3171/2014.9.FOCUS14496

[4] SEMENZA, GL Defining the role of hypoxia-inducible factor 1 in cancer biology and therapeutics. Oncogene 2010; 29: 625-634 http://dx.doi.org/10.1038/onc.2009.441

[5] XU CS, WANG ZF, HUANG XD, DAI LM, CAO CJ et al. Involvement of ROS-alpha v beta 3 integrin-FAK/Pyk 2 in the inhibitory effect of melatonin on U251 glioma cell migration and invasion under hypoxia. J Transl Med 2015; 13: 95 http:// dx.doi.org/10.1186/s12967-015-0454-8

[6] XU H, RAHIMPOUR S, NESVICK CL, ZHANG X, MA $\mathrm{J}$ et al. Activation of hypoxia signaling induces phenotypic transformation of glioma cells: implications for bevacizumab antiangiogenic therapy. Oncotarget 2015; 6: 11882-11893 http://dx.doi.org/10.18632/oncotarget.3592

[7] YUE P, TURKSON J Targeting STAT3 in cancer: how successful are we?. Expert Opin Investig Drugs 2009; 18: 45-46 http://dx.doi.org/10.1517/13543780802565791

[8] KAMRAN MZ, PATIL P, GUDE RP Role of STAT3 in cancer metastasis and translational advances. Biomed Res Int 2013; 2013: 421821

[9] DARNELL JE STATs and gene regulation. Science 1997; 277: 1630-1635 http://dx.doi.org/10.1126/science.277.5332.1630

[10] BROMBERG J Stat proteins and oncogenesis. J Clin Invest 2002; 109: 1139-1142 http://dx.doi.org/10.1172/ JCI0215617

[11] WEI G, MINGLIANG Z, YONG C, SUYANG G Expression of signal transducer and activator of transcription 3 in breast cancer and its clinical significance. J Cancer Res Ther 2015; 11: 56 http://dx.doi.org/10.4103/0973-1482.163840

[12] HAN Z, WANG X, MA L, CHEN L, XIAO M et al. Inhibition of STAT3 signaling targets both tumor-initiating and differentiated cell populations in prostate cancer. Oncotarget 2014; 5: 8416 http://dx.doi.org/10.18632/oncotarget.2314
[13] RAHAMAN SO, HARBOR PC, CHERNOVA O, BARNETT GH, VOGELBAUM MA et al. Inhibition of constitutively active Stat 3 suppresses proliferation and induces apoptosis in glioblastoma multiforme cells. Oncogene 2002; 21: 8404-8413 http://dx.doi.org/10.1038/sj.onc.1206047

[14] KIM JE, PATEL M, RUZEVICK J, JACKSON CM, LIM M STAT3 activation in glioblastoma: biochemical and therapeutic implications. Cancers 2014; 6: 376-395. http://dx.doi. org/10.3390/cancers6010376

[15] BOWMAN T, GARCIA R, TURKSON J, JOVE R STATs in oncogenesis. Oncogene 2000; 19: 2474-2488 http://dx.doi. org/10.1038/sj.onc. 1203527

[16] SHIZAWA T, MIYATA H, IIZUKA A, KOMIYAMA M, OSHITA C et al. Effect of the STAT3 inhibitor STX-0119 on the proliferation of cancer stem-like cells derived from recurrent glioblastoma. Int J Oncol 2013; 43: 219-227

[17] FUH B, SOBO M, CEN L, JOSIAH D, HUTZEN B et al. LLL-3 inhibits STAT3 activity, suppresses glioblastoma cell growth and prolongs survival in a mouse glioblastoma model. Br J Cancer 2009; 100: 106-112 http://dx.doi.org/10.1038/sj.bjc.6604793

[18] GAO L, LI F, DONG B, ZHANG J, RAO Y et al. Inhibition of STAT3 and ErbB2 suppresses tumor growth, enhances radiosensitivity, and induces mitochondria-dependent apoptosis in glioma cells. Int J Radiat Oncol Biol Phys 2010; 77: 1223-1231 http://dx.doi.org/10.1016/j.ijrobp.2009.12.036

[19] LI GH, WEI H, LV SQ, JI H, WANG DL Knockdown of STAT3 expression by RNAi suppresses growth and induces apoptosis and differentiation in glioblastoma stem cells. Int J Oncol 2010; 37: 103-110

[20] LUJAMBIO A, LOWE SW The microcosmos of cancer. Nature 2012; 482(7385): 347-355 http://dx.doi.org/10.1038/ $\underline{\text { nature } 10888}$

[21] MISSO G, DI MARTINO MT, DE ROSA G, FAROOQI AA, LOMBARDI A et al. Mir-34: a new weapon against cancer?. Mol Ther Nucleic Acids 2014; 3: e194 http://dx.doi. org/10.1038/mtna.2014.47

[22] ZHANG DG, ZHENG JN, PEI DS P53/microRNA-34 -induced metabolic regulation: new opportunities in anticancer therapy. Mol Cancer 2014; 13: 115 http://dx.doi. org/10.1186/1476-4598-13-115

[23] ROKAVEC M, ONER MG, LI H, JACKSTADT R, JIANG L et al. IL-6R/STAT3/miR-34a feedback loop promotes EMTmediated colorectal cancer invasion and metastasis. J Clin Invest 2014; 124: $1853 \mathrm{http://dx.doi.org/10.1172/JCI73531}$

[24] WANG Y, CATANA F, YANG Y, RODERICK R, VAN BREEMEN RB An LC-MS method for analyzing total resveratrol in grape juice, cranberry juice, and in wine. J Agric Food Chem 2002; 50: 431-435 http://dx.doi.org/10.1021/jf010812u

[25] BURNS J, YOKOTA T, ASHIHARA H, LEAN ME, CROZIER A Plant foods and herbal sources of resveratrol. J Agric Food Chem 2002; 50: 3337-3340 http://dx.doi.org/10.1021/ jf0112973

[26] SOLEAS GJ, DIAMANDIS EP, GOLDBERG DM Wine as a biological fluid: history, production, and role in disease prevention. J Clin Lab Anal 1997; 11: 287-313 http:// dx.doi.org/10.1002/(SICI) 1098-2825(1997)11:5<287::AIDLCLA6>3.0.CO;2-4 
[27] HAN G, XIA J, GAO J, INAGAKI Y, TANG W et al. Anti-tumor effects and cellular mechanisms of resveratrol. Drug Discov Ther 2015: 9: 1-12 http://dx.doi.org/10.5582/ ddt.2015.01007

[28] YANG X, LI X, REN J From French Paradox to cancer treatment: anti-cancer activities and mechanisms of resveratrol. Anticancer Agents Med Chem 2014; 14: 806-825 http://dx.doi. org/10.2174/1871520614666140521121722

[29] BAUR JA, SINCLAIR DA Therapeutic potential of resveratrol: the in vivo evidence. Nat Rev Drug Discov 2006; 5: 493-506 http://dx.doi.org/10.1038/nrd2060

[30] GAO Q, YUAN Y, GAN HZ, PENG Q Resveratrol inhibits the hedgehog signaling pathway and epithelial-mesenchymal transition and suppresses gastric cancer invasion and metastasis. Oncol Lett 2015; 9: 2381-2387 http://dx.doi.org/10.3892/ ol.2015.2988

[31] KOZUKI Y, MIURA Y, YAGASAKI K Resveratrol suppresses hepatoma cell invasion independently of its anti-proliferative action. Oncol Lett 2001; 167: 151-156 http://dx.doi. org/10.1016/s0304-3835(01)00476-1

[32] CASTINO R, PUCER A, VENERONI R, MORANI F, PERACCHIO $\mathrm{C}$ et al. Resveratrol Reduces the Invasive Growth and Promotes the Acquisition of a Long-Lasting Differentiated Phenotype in Human Glioblastoma Cells. J Agric Food Chem 2011; 59: 4264-72 http://dx.doi.org/10.1021/ jf104917q

[33] WANG Q, XU J, ROTTINGHAUS GE, SIMONYI A, LUBAHN D et al. Resveratrol protects against global cerebral ischemic injury in gerbils. Brain Res 2002; 958: 439-447 http:// dx.doi.org/10.1016/S0006-8993(02)03543-6

[34] KIM YS, SULL JW, SUNG HJ Suppressing effect of resveratrol on the migration and invasion of human metastatic lung and cervical cancer cells. Mol Biol Rep 2012; 39: 8709-8716 http:// dx.doi.org/10.1007/s11033-012-1728-3

[35] TANG FY, SU YC, CHEN NC, HSIEH HS, CHEN KS Resveratrol inhibits migration and invasion of human breast-cancer cells. Mol Nutr Food Res 2008; 52: 683-691 http://dx.doi. org $/ 10.1002 / \mathrm{mnfr} .200700325$

[36] DANG CV c-Myc target genes involved in cell growth, apoptosis, and metabolism. Molecular and cellular biology 1999; 19: 1-11 http://dx.doi.org/10.1128/MCB.19.1.1

[37] BHATTACHARYA S, RAY RX, JOHNSON LX STAT3mediated transcription of Bcl-2, Mcl-1 and c-IAP2 prevents apoptosis in polyamine-depleted cells. Biochem J 2005; 392 : 335-344 http://dx.doi.org/10.1042/BJ20050465

[38] SILVER DL, NAORA H, LIU J, CHENG W, MONTELL DJ Activated signal transducer and activator of transcription (STAT) 3 localization in focal adhesions and function in ovarian cancer cell motility. Cancer Res 2004; 64: 3550-3558 http://dx.doi.org/10.1158/0008-5472.CAN-03-3959

[39] NG DC, LIN BH, LIM CP, HUANG G, ZHANG T et al. Stat3 regulates microtubules by antagonizing the depolymerization activity of stathmin. J Cell Biol 2006; 172: 245-257 http:// dx.doi.org/10.1083/jcb.200503021

[40] YANG YH, LI DL, BI XY, SUN L, YU XJ et al. Acetylcholine Inhibits LPS-Induced MMP-9 Production and Cell Migration via the a7 nAChR-JAK2/STAT3 Pathway in RAW264.7
Cells. Cell Physiol Biochem 2015; 36: 2025-2038 http://dx.doi. org/10.1159/000430170

[41] SCHÜTZ A, RÖSER K, KLITZSCH J, LIEDER F, ABERGER $\mathrm{F}$ et al. Lung Adenocarcinomas and Lung Cancer Cell Lines Show Association of MMP-1 Expression With STAT3 Activation. Transl Oncol 2015; 8: 97-105 http://dx.doi.org/10.1016/j. tranon.2015.02.002

[42] AHN JH, CHOI YS, CHOI JH Leptin promotes human endometriotic cell migration and invasion by up-regulating MMP-2 through the JAK2/STAT3 signaling pathway. Transl Oncol 2015; 21: 792-802 http://dx.doi.org/10.1093/molehr/ gav039

[43] BRANTLEY EC, BENVENISTE EN Signal transducer and activator of transcription-3: a molecular hub for signaling pathways in gliomas. Mol Cancer Rs 2008; 6: 675-684 http:// dx.doi.org/10.1158/1541-7786.MCR-07-2180

[44] CALIN GA, CROCE CM MicroRNA signatures in human cancers. Nat Rev Cancer 2006; 6: 857-866 http://dx.doi. org/10.1038/nrc1997

[45] KULSHRESHTHA R, FERRACIN M, WOJCIK SE, GARZON R, ALDER $\mathrm{H}$ et al. A microRNA signature of hypoxia. Mol Cell Biol 2007; 27: 1859-1867 http://dx.doi.org/10.1128/ MCB.01395-06

[46] JIANG LH, GE MH, HOU XX, CAO J, HU SS et al. miR-21 regulates tumor progression through the miR-21-PDCD4Stat 3 pathway in human salivary adenoid cystic carcinoma. Lab Invest 2015 http://dx.doi.org/10.1038/labinvest.2015.105

[47] FANA Z, CUI H, XU X, LIN Z, ZHANG X et al. MiR-125a suppresses tumor growth, invasion and metastasis in cervical cancer by targeting STAT3. Oncotarget 2015; 6: 25266-25280 http://dx.doi.org/10.18632/oncotarget.4457

[48] QU JQ, YI HM, YE X, LI LN, ZHU JF et al. MiR-23a sensitizes nasopharyngeal carcinoma to irradiation by targeting IL-8/ Stat3 pathway. Oncotarget 2015; 6: 28341-28356 http://dx.doi. org/10.18632/oncotarget.5117

[49] LI L, YUAN L, LUO J, GAO J, GUO J et al MiR-34a inhibits proliferation and migration of breast cancer through downregulation of Bcl-2 and SIRT1. Clin Exp Med 2013; 13: 109-117 http://dx.doi.org/10.1007/s10238-012-0186-5

[50] LIU C, KELNAR K, LIU B, CHEN X, CALHOUN-DAVIS T et al. The microRNA miR-34a inhibits prostate cancer stem cells and metastasis by directly repressing CD44. Nat Med 2011; 17: 211-215 http://dx.doi.org/10.1038/nm.2284

[51] LI N, FU H, TIE Y, HU Z, KONG W et al. miR-34a inhibits migration and invasion by down-regulation of c-Met expression in human hepatocellular carcinoma cells. Cancer Lett 2009; 275: 44-53 http://dx.doi.org/10.1016/j.canlet.2008.09.035

[52] DU R, SUN W, XIA L, ZHAO A, YU Y et al. Hypoxia-induced down-regulation of microRNA-34a promotes EMT by targeting the Notch signaling pathway in tubular epithelial cells. PloS one 2012; 7: e30771 http://dx.doi.org/10.1371/journal. pone.0030771

[53] KANG SH, YU MO, PARK KJ, CHI SG, PARK DH et al. Activated STAT3 regulates hypoxia-induced angiogenesis and cell migration in human glioblastoma. Neurosurgery 2010; 67: 1386-1395 http://dx.doi.org/10.1227/ NEU.0b013e3181f1c0cd 